\title{
Outcomes and Toxicology of Herbal Drugs in Alcoholic Hepatitis - A Single Center Experience from India
}

\author{
Cyriac Abby Philips*1 ${ }^{1}$, Sasidharan Rajesh ${ }^{2}$, Tom George ${ }^{2}$, Rizwan Ahamed ${ }^{3}$, Sandeep Kumbar ${ }^{3}$ \\ and Philip Augustine ${ }^{3}$
}

\author{
${ }^{1}$ The Liver Unit and Monarch Liver Lab, Cochin Gastroenterology Group, Ernakulam Medical Center, Kochi, Kerala, India; \\ ${ }^{2}$ Interventional Radiology, Department of Gastroenterology and Hepatology, Cochin Gastroenterology Group, Ernakulam Medical \\ Center, Kochi, Kerala, India; ${ }^{3}$ Gastroenterology and Advanced G.I. Endoscopy, Cochin Gastroenterology Group, Ernakulam \\ Medical Center, Kochi, Kerala, India
}

\begin{abstract}
Background and Aims: We aimed to study clinical outcomes and liver biopsy features of alcoholic hepatitis (AH) patients on complementary and alternative medicines (CAMs) and to analyze the retrieved drugs for chemical and toxic components linked to drug-induced liver injury. Methods: We retrospectively assessed clinical, biochemical and liver biopsy features of AH patients on CAM with drug-induced liver injury ( $\mathrm{AH}-\mathrm{CAM}, n=27$ ) and compared them to a control group (classical $\mathrm{AH}, n=29$ ) on standard of care. Patients without liver biopsy evaluation and other causes for liver disease were excluded. Samples of the CAMs $(n=42)$ from patients were retrieved and assessed for chemical and toxins. Results: All were males, and significantly worse clinical presentation, biochemical severity, and liver disease scores were notable in patients with AH-CAM. Traditional Ayurvedic-polyherbal formulations were the most commonly used CAM. On liver histology, varying grades of severe-necrosis, severe hepatocellular, canalicular, cholangiolar cholestasis with predominant lymphocytic-portal-inflammation and varying grades of interface-hepatitis were noted in $\mathrm{AH}$ CAM. Analysis of CAMs revealed presence of heavy metals up to 100,000 times above detectable range and adulterants, such as antibiotics, chemotherapy agents, nonsteroidal anti-inflammatory drugs, alcohols, antidepressants, anxiolytics, and recreational drugs. On follow up, a significantly higher number of patients with $\mathrm{AH}$ on CAM died at end of 1,3 - and- 6 -months compared to controls ( $37 \%$ vs. $83 \%$, $29 \%$ vs. $62 \%, 18 \%$ vs. $52 \%$ respectively; $p<0.001)$. Conclusions: Patients with $\mathrm{AH}$ and CAM-related druginduced liver injury have extremely poor short-term survival in the absence of liver transplantation compared to those patients with $\mathrm{AH}$ on evidence-based management. Early transplant referral and educating on and curbing of CAM use in severe liver disease through strict monitoring of
\end{abstract}

Keywords: Hepatitis; Alcohol; CAM; DILI; Ayurveda.

Abbreviations: $\mathrm{AH}$, alcoholic hepatitis; ACLF, acute-on-chronic liver failure; CAM, complementary and alternative medicine; DILI, drug-induced liver injury; GC-MS/ MS, gas chromatography coupled to tandem mass spectrometry method; SD standard deviation.

Received: 5 September 2019; Revised: 4 October 2019; Accepted: 24 October 2019

* Correspondence to: Cyriac Abby Philips, The Liver Unit and Monarch Liver Lab, Cochin Gastroenterology Group, Ernakulam Medical Center, Symphony, Automobile Road, Palarivattom, Cochin 682025, India. Tel/Fax: +91-484-2907000, E-mail: abbyphilips@gmail.com unregulated traditional health practices can help ease the burden of liver-related death.

Citation of this article: Philips CA, Rajesh S, George T, Ahamed R, Kumbar S, Augustine P. Outcomes and toxicology of herbal drugs in alcoholic hepatitis - A single center experience from India. J Clin Transl Hepatol 2019;7(4):329-340. doi: $10.14218 /$ JCTH.2019.00043.

\section{Introduction}

Alcoholic hepatitis $(\mathrm{AH})$ is a catastrophic entity associated with high mortality, occurring in the natural history of alcoholic liver disease in persons with continued heavy or binge alcohol use. In patients with underlying alcoholic cirrhosis, it can present as acute-on-chronic liver failure (ACLF), with very poor prognosis and high mortality in the absence of best medical standard of care or liver transplantation. ${ }^{1,2}$ Recommended treatment options for $\mathrm{AH}$, even though beneficial in select patients in the short term, are not without risk - such as sepsis and multiorgan failure with corticosteroid use, rapidly progressive extrahepatic organ failures and high risk of alcohol relapse that foretell poor outcomes with liver transplantation. ${ }^{3,4}$

In regions entrenched in complementary and alternative medicine (CAM) medical practices, such as India, the use of alternative systems of medicines, such as Ayurveda, Siddha, Homeopathy, Unani and proprietary herbal drugs for management of acute as well as chronic liver diseases, is on the rise. Multiple studies encompassing single and as well as multiple centers have shed light on hepatotoxicity associated with CAM drugs. Drug-induced liver injury (DILI) and the toxicology of implicated Ayurvedic drugs among the healthy general population and patients with cirrhosis, leading to the syndrome of ACLF, have been demonstrated recently. ${ }^{5,6}$ The false belief of a safer drug profile, cheaper treatment cost and easy approachability and availability of CAM-related health services, along with rampant advertisements regarding the same on social media, has facilitated the growth of CAMrelated health seeking practices, especially among patient populations with chronic diseases. However, this has only added to the liver disease burden, leading to higher resource utilization and exhaustive treatments with greater financial implications. ${ }^{7-10}$

Clinical outcomes with CAM use among patients with acute viral hepatitis and chronic liver disease, including alcoholic 
Philips C.A. et al: CAM use in alcoholic hepatitis and outcomes

liver disease, have been reported before; ${ }^{11-16}$ outcomes associated with CAM use among patients with AH have not. In this novel study, we determined the clinical outcomes, liver histopathological patterns and toxicology of CAM-related DILI among patients with $\mathrm{AH}$ compared to a group of severe $\mathrm{AH}$ patients on standard of care. Our findings are noteworthy in improving education with regards to CAM-related healthseeking behavior among patients with severe liver disease, so as to curb unwarranted resource utilization, impart timely and sensible therapeutic options, and reduce mortality directly related to liver-related events.

\section{Methods}

\section{Patients}

We conducted a retrospective analysis of patients with alcoholic liver disease in a dedicated liver disease unit of a tertiary care center to identify those fulfilling the clinical definition of $\mathrm{AH}^{17}$ Those who developed jaundice (clinically defined as yellowish discoloration of the eyes and urine) with continuous heavy drinking or binge alcohol use in the preceding 2 months were screened for inclusion. Patients were grouped into those with and without liver tests at the onset of symptoms. In the former, those with serum total bilirubin $>3.5 \mathrm{mg} / \mathrm{dL}$ and aspartate aminotransferase to alanine aminotransferase ratio of $>2$ were considered further for liver biopsy. Those undergoing liver biopsy and fulfilling liver histology criteria for $\mathrm{AH}$ were included as the control group. The former as well as latter patients, with probable $\mathrm{AH}$, consuming CAMs for treatment of liver disease and presenting to the liver unit after consumption of CAM were advised to undergo liver biopsy evaluation. Those patients with probable $\mathrm{AH}$ and CAM use who consented to liver biopsy were placed into the AH-CAM group.

Prior to liver biopsy evaluation, all patients underwent extensive evaluation for other causes of acute hepatitis and were excluded from the study at specified time periods, in the event of alternate diagnosis. Etiology workup included evaluation for acute viral hepatitis $A, B, C$ and $E$, herpes zoster, herpes simplex, Epstein-Barr virus, cytomegalovirus, Dengue virus, malaria parasite, human immunodeficiency virus, antibodies to Leptospira in those clinically indicated [acute febrile illness and jaundice associated with severe headache, myalgia (particularly calf muscle) and prostration associated with conjunctival suffusion, bleeding diathesis, renal and pulmonary involvement with or without central nervous system symptoms and signs], autoantibodies for autoimmune hepatitis (including antinuclear, anti-smooth muscle, anti-liverkidney-microsomal antibodies) serum ceruloplasmin, $24 \mathrm{~h}$ urine for copper, ophthalmology evaluation for KayserFleischer ring, use of other known hepatotoxic agents other than CAMs, imaging for primary sclerosing cholangitis, gall bladder and bile duct diseases, and pyogenic and amoebic liver abscesses when clinically indicated. Patients with hepatocellular carcinoma, portal vein thrombosis and those who did not provide consent for liver biopsy were excluded. Ultimately, only those patients with biopsy proven definite $\mathrm{AH}$ and those with probable $\mathrm{AH}$ with additional features of CAMDILI on liver biopsy were included in the comparative study. All procedures performed in the study were in accordance with the ethical standards of the institutional research committee and with the 1964 Helsinki Declaration and its later amendments or comparable ethical standards.
Methodology of drug chemical analysis and toxicology

Heavy metal contamination, presence of potential hepatotoxic volatile organic compounds, adulterants, and insecticides and pesticides were analyzed in the retrieved drug samples as per previously published standard methodology. ${ }^{6,18-22}$ Heavy metal concentration was determined by inductively coupled plasma-atomic emission spectrometer (IRIS Intrepid II XSP Duo; Thermo Electron Corp., Munich, Germany). Methodology, chemical standards, reagents, and vials were acquired as per standards set by the United States Environmental Protection Agency, methods 5021A, 8015, 8021 , and 8260. Hepatotoxic volatile organic compounds' qualitative analyses were performed using gas chromatography coupled to tandem mass spectrometry method (GC-MS/ MS; Thermo Fisher Scientific, Waltham, MA, USA). Pesticide residue analysis was also performed using the triple quadruple GC-MS/MS (GC TRACE 1300 with TSQ EVO 8000 MS). Briefly, the required quantity of sample was extracted and homogenized. Extract weighing $10 \mathrm{~g}$ was admixed (according to the sample weight, analytical chemicals proportionally used as per standardized guidelines) with $10 \mathrm{~mL}$ of acetonitrile. Thereafter, $10 \mathrm{~g}$ of magnesium sulphate sodium acetate mixture was prepared and vortexed, followed by centrifugation at $2000 \mathrm{rpm}$ for $5 \mathrm{~m}$. A $5 \mathrm{~mL}$ aliquot was taken from the supernatant and cleaned up using a PSA, C18 \& GCB sorbent removal kit to exclude all of the matrix interfering materials in the sample, during the dispersive solid phase extraction. Vortexing and centrifugation at $10000 \mathrm{rpm}$ was further done for $5 \mathrm{~m}$. To detect and analyze organochlorine and organophosphorus pesticide residue, $1 \mathrm{~mL}$ of the supernatant was taken and $1 \mu \mathrm{L}$ was injected into the gas chromatograph. Identification and quantification were carried out by mass spectrometer using organochlorine and organophosphorus pesticide standards available. For qualitative corticosteroid analysis, 1 $\mu \mathrm{L}$ of the extract was injected into the gas chromatograph and qualitative identification of all possible peaks of steroids available in the GC-MS/MS temperature programming method (3500C max) was made and noted. Further augmentation of detection process was done using the Salkowski and Lieberman Burchardt tests. Further to these tests, $1 \mu \mathrm{L}$ of the sample extract was injected into the gas chromatograph and qualitative identification of all possible peaks of organic compounds available in the GC-MS/MS temperature programming method was performed so as not to miss all identifiable substances in the drug sample. For alcohol analysis and quantification, approximately $1 \mathrm{~mL}$ of sample was added to a sample vial and mixed for at least $2 \mathrm{~m}$ by mechanical shaking. The vial was then placed in the head space analyzer and the sample was heated to $100{ }^{\circ} \mathrm{C}$ for $25 \mathrm{~m}$ with periodic mechanical shaking. A representative sample of 1 $\mathrm{mL}$ of this prepared mixture was then injected to the gas chromatograph and identification and quantification of detected alcohols were done by mass spectrophotometer using procured and defined standards. Similarly, using the GC-MS/MS standardized technique, volatile organic compounds were detected and identified using the equilibriumbased static head space method for solid samples and the purge-and-trap method for liquid samples.

\section{Statistical analysis}

Statistical analysis was performed using MedCalc Statistical Software (Ostend, Belgium). Data are presented as mean and 
standard deviation (SD) or as median and range between brackets as applicable. Shapiro-Wilk test was used to test normality and Levene's test was utilized to check for equality of variances. Chi-square and Fisher's exact tests were used to compare nominal variables. Mann-Whitney's $U$ test was used to evaluate continuous variables. One-way analysis of variance (ANOVA) was used to test for differences at baseline between the means of investigational variables of groups and Kruskal-Wallis test with pairwise comparisons on post hoc analysis between categorical, noncontinuous variables. A $p$-value $<0.05$ was considered significant. The probability of patients surviving up to the study end-point was calculated using the Kaplan-Meier method and graphically represented by the survival time curve. Comparison between the survival curves was made using the log-rank test and a $p$-value $<0.05$ was considered significant.

\section{Results}

\section{Patient screening and inclusion}

From November 2017 to February 2019, 108 patients with jaundice and continuous heavy alcohol use or binge alcohol drinking 2 months prior to onset of jaundice were screened for inclusion. A total of 72 patients were found to have total bilirubin $>3.5 \mathrm{mg} / \mathrm{dL}$ with aspartate aminotransferase: alanine aminotransferase ratio $>2$ on liver function test evaluation after onset of jaundice. Nine of these patients were excluded in view of alternative causes of acute icteric hepatitis. Of the remaining 51 patients, 29 consented to liver biopsy and were included in the control $(\mathrm{AH})$ group and 12 patients consumed CAMs after clinical diagnosis of probable $\mathrm{AH}$, of which 8 consented to liver biopsy. A total of 36 patients ( $n=108)$ did not undergo liver function tests after onset of jaundice and directly consumed CAMs as the treatment for jaundice. Among these, 7 patients were excluded in view of identification of alternate causes for acute icteric hepatitis. Of the remaining 29 patients, 19 patients consented to liver biopsy, giving a total of 27 patients in the AH-CAM group. The complete patient screening, exclusion causes, and grouping are shown in Fig. 1.

\section{Patient characteristics}

In both groups, all patients were males with mean age ( $(\mathrm{SD})$ $49.4 \pm 9.8$ and $45.8 \pm 9.7$ years in $\mathrm{AH}$ and $\mathrm{AH}-\mathrm{CAM}$ group respectively. Seven patients $(26 \%, n=27)$ in the AH-CAM group were obese alcoholics. In the AH-CAM group, 3 $(11 \%), 1(4 \%), 11(41 \%)$ and $6(22.2 \%)$ patients had chronic disease, such as systemic hypertension, hypothyroidism and diabetes mellitus respectively, which was comparable to those in the $\mathrm{AH}$ group; there were none in the $\mathrm{AH}$ group, while $6(22 \%)$ in the AH-CAM group had dyslipidemia $(p=0.007)$. Ascites at presentation was comparable at baseline, in $79 \%(n=23 / 29)$ and $70 \%(n=19 / 27)$ of patients in the $\mathrm{AH}$ and $\mathrm{AH}$-CAM group respectively, while acute variceal bleeding at presentation was significantly higher among patients in the AH-CAM group $(40.7 \%$ vs. $10.3 \%, p=$ 0.009 ). On follow up, at the end of 180 days, a trend towards higher variceal bleeding events was notable among patients in the AH-CAM group compared to the classical $\mathrm{AH}$ patients $(n=13 / 27,48 \%$ vs. $n=7 / 29,24 \% ; p=0.06)$. A trend towards higher severity of ascites (grade 3 , tense) at admission was noted in the AH-CAM group $(n=8 / 27,29.6 \%$ vs. $n=3 / 29,10.3 \%, p=0.07)$. The presence of hepatic encephalopathy at admission was not significantly different between the groups (51.7\% AH vs. $59.3 \%$ AH-CAM). However, a higher proportion of patients in the AH-CAM group had more severe grades of hepatic encephalopathy (grade 3/4) at presentation $(22.2 \%, n=6 / 27)$ when compared to patients with classical $\mathrm{AH}(13.7 \%, n=4 / 29)$ but the difference did not reach statistical significance. Lower $(0+1)$ and higher $(2+3)$ grades of ACLF were comparable between groups at baseline, even though lower grades were prominent in patients with classical $\mathrm{AH}$ compared to the $\mathrm{AH}-$ CAM group $(65.5 \%$ vs. $51.8 \%)$. The comparative patient characteristics between groups are shown in Table 1.

\section{Investigational characteristics and severity of liver disease}

In patients in the AH-CAM group, the mean hemoglobin was lower (possibly due to the higher number of patients with variceal bleeding) and leukocytosis was higher at presentation, even though this difference did not reach statistical significance. Significant thrombocytopenia was notable among patients in the AH-CAM group compared to classical $\mathrm{AH}$ patients (median, 81.0 vs. $101.0 \times 10^{9} / \mathrm{L}$ respectively; $p=0.02$ ). Hyperbilirubinemia was significantly more severe in patients with $\mathrm{AH}$ consuming CAM $(18.8 \pm 9.7 \mathrm{mg} / \mathrm{dL}$ vs. $12.6 \pm 6.7 \mathrm{mg} / \mathrm{dL} ; p=0.007)$. Presence of coagulation failure, hyponatremia, acute kidney injury and hypoalbuminemia were comparable between groups. The severity of $\mathrm{AH}$ (defined as the discriminant function) was significantly higher in patients on CAM compared to classical $\mathrm{AH}$ patients (median, 80.8 vs. 61.0 respectively, $p=0.01$ ). The presence of autoantibodies was notable in patients on CAM therapy $(23.6 \%)$ in comparison to classical $\mathrm{AH}$ patients $(2.8 \%, p=$ 0.02 ). The severity of liver disease (Child Pugh score and the Chronic Liver Failure score) were significantly higher in patients with $\mathrm{AH}$ on CAM therapy. However, the model for end-stage liver disease sodium score, ACLF grades and Chronic Liver Failure-C-ACLF scores were comparable between groups. The comparative investigational and liver disease severity characteristics between groups are shown in Table 2 .

\section{Comparative liver histopathology of patients between groups}

Steatosis of predominantly mixed type, ballooning of hepatocytes, and pericellular fibrosis were present in the liver histology of all patients in both groups. However, milder grades of steatosis significantly predominated liver histology of patients with AH on CAM $(n=13 / 27,48.1 \%)$ compared to patients with classical $A H$, in whom a moderate degree of steatosis was noted $(n=19 / 29,65.5 \% ; p=0.01)$. The predominant region of inflammation was lobular in $75.9 \%$ of patients with classical $\mathrm{AH}$, while it was portal-based in $77.8 \%$ of patients in the AH-CAM group ( $p<0.001)$. In $63 \%$ of patients in the AH-CAM group, the predominant type of inflammation was lymphocytic, while in $89.7 \%$ of patients with classical $\mathrm{AH}$, it was neutrophilic $(p<0.001)$. A trend towards higher occurrence for neutrophilic satellitosis was notable in the classical $\mathrm{AH}$ group (55.2\%) compared to patients in the AH-CAM group (29.6\%, $p=0.05)$. MalloryDenk bodies were noted in patients in both groups, with significantly higher predominance in classical AH patients $(100 \%)$, compared to patients with $\mathrm{AH}$ on CAMs $(77.8 \%$, 


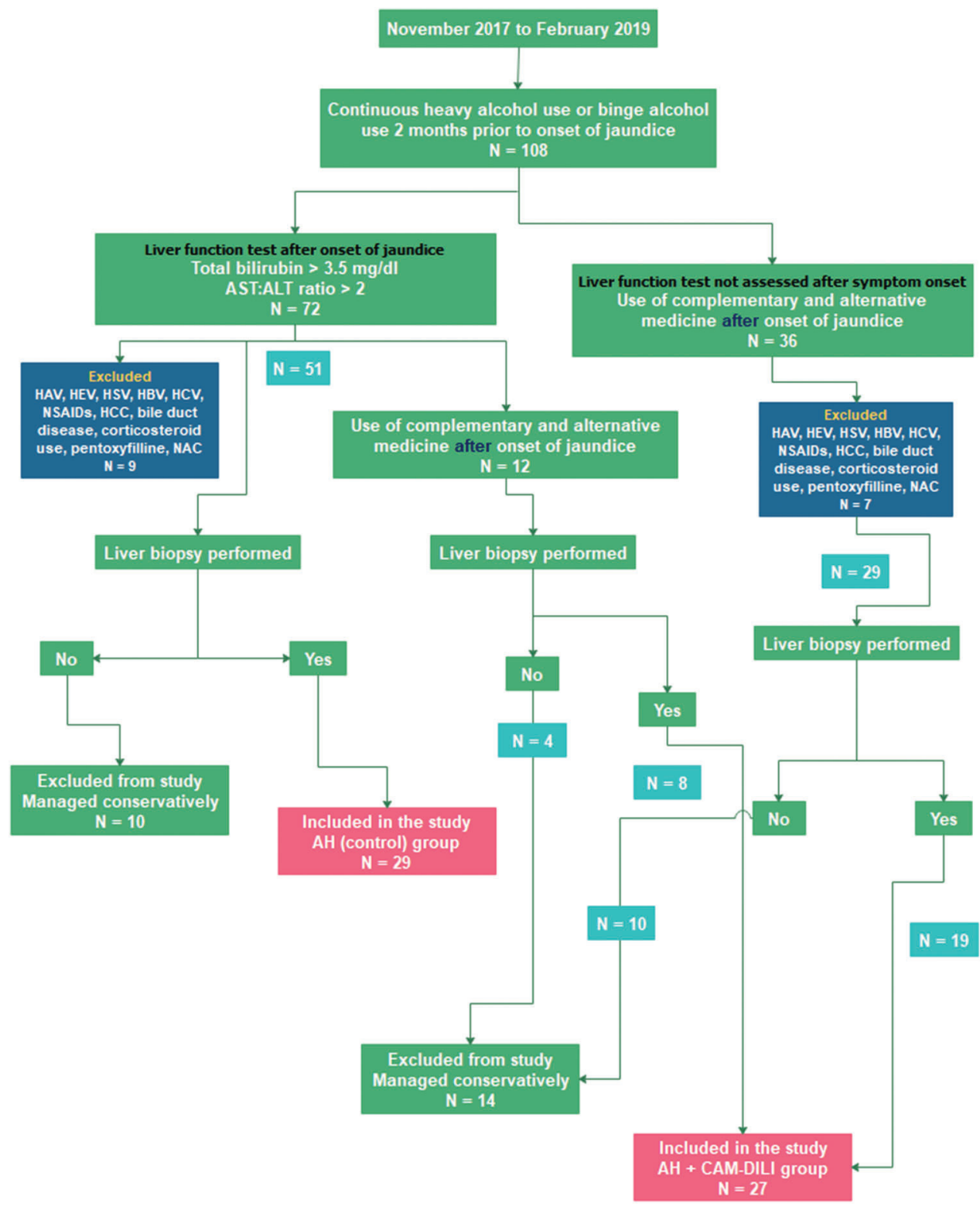

Fig. 1. Enrolment and inclusion of patients in the study.

$p=0.008)$. An increased presence of megamitochondria with trend towards significance was noted among patients with classical $\mathrm{AH}$ compared to $\mathrm{AH}$ patients consuming CAMs (27.6\% vs. $7.4 \%, p=0.05)$. Interestingly, the presence of foamy degeneration of hepatocytes were found to be higher in patients of $\mathrm{AH}$ on CAMs $(n=11 / 27,40.7 \%)$ compared to those with classical AH $(n=5 / 29,17.2 \% ; p=0.05)$. Underlying cirrhosis was seen in $81.5 \%$ and $89.7 \%$ of patients in the AH-CAM and classical AH groups respectively $(p=0.38)$.

Apart from the classical features seen on liver histopathology in $\mathrm{AH}$ patients, variable additional findings were notable in patients with $\mathrm{AH}$ consuming CAMs. Eosinophilic infiltration of the portal and lobular areas was striking in patients with $\mathrm{AH}$ on CAMs only compared to those with classical AH (44.4\% vs. $0 \%, p<0.001)$. Plasma cell infiltrates were significantly more common in patients with $\mathrm{AH}$ consuming CAMs compared to classical $\mathrm{AH}$ ( $37 \%$ vs. $6.9 \% ; p=0.006$ ). Interface hepatitis was not seen in the liver biopsy of patients with classical $\mathrm{AH}$ but was significantly higher in patients with $\mathrm{AH}$ consuming CAMs $(n=19 / 27,70.4 \% ; p<0.001)$, with almost onethird of the patients demonstrating severe grades of interface hepatitis. The presence of hepatocyte necrosis was more commonly noted in patients with severe $\mathrm{AH}$ consuming CAMs $(19 / 27,70.4 \%$ vs. 5/29, $17.2 \% ; p<0.001)$. Among patterns of necrosis, periportal necrosis $(p=0.003)$, bridging necrosis $(p=0.004)$, confluent necrosis $(p=0.003)$ and submassive necrosis $(p=0.01)$ were significantly more conspicuous in patients who consumed CAMs, while spotty necrosis and perivenular necrosis patterns of liver injury were comparable between both groups. Significantly larger proportion of 
Philips C.A. et al: CAM use in alcoholic hepatitis and outcomes

Table 1. Patient characteristics between groups

\begin{tabular}{|c|c|c|c|c|}
\hline \multicolumn{2}{|l|}{ Descriptive, $(n, \%)$} & AH-CAM group, $n=27$ & Classical AH group, $n=29$ & $p$ value \\
\hline \multicolumn{2}{|l|}{ Obesity } & $7(25.9 \%)$ & $0(0 \%)$ & 0.003 \\
\hline \multicolumn{2}{|l|}{ Systemic hypertension } & $3(11.1 \%)$ & $2(6.9 \%)$ & 0.58 \\
\hline \multicolumn{2}{|l|}{ Hypothyroidism } & $1(3.7 \%)$ & $0(0 \%)$ & 0.30 \\
\hline \multicolumn{2}{|l|}{ Diabetes mellitus } & $11(40.7 \%)$ & $9(31 \%)$ & 0.45 \\
\hline \multicolumn{2}{|l|}{ Dyslipidemia } & $6(22.2 \%)$ & $0(0 \%)$ & 0.007 \\
\hline \multicolumn{2}{|c|}{ Hepatic encephalopathy (any grade) } & $16(59.3 \%)$ & $15(51.7 \%)$ & 0.57 \\
\hline \multirow[t]{2}{*}{ Hepatic encephalopathy } & Grade $1+2$ & $9(33.3 \%)$ & $13(44.8 \%)$ & 0.38 \\
\hline & Grade $3+4$ & $6(22.2 \%)$ & $4(13.7 \%)$ & 0.41 \\
\hline \multicolumn{2}{|l|}{ Ascites (any grade) } & $19(70.4 \%)$ & $23(79.3 \%)$ & 0.44 \\
\hline & Grade 1 & $3(11.1 \%)$ & $7(24.1 \%)$ & 0.20 \\
\hline & Grade 2 & $11(40.7 \%)$ & $14(48.3 \%)$ & 0.57 \\
\hline & Grade 3 & $8(29.6 \%)$ & $3(10.3 \%)$ & 0.07 \\
\hline \multicolumn{2}{|l|}{ Acute variceal bleeding } & $11(40.7 \%)$ & $3(10.3 \%)$ & 0.009 \\
\hline \multicolumn{2}{|c|}{ Acute variceal bleeding on follow up (at 180 days) } & $13(48.1 \%)$ & $7(24.1 \%)$ & 0.06 \\
\hline \multirow[t]{2}{*}{ ACLF grades } & $0+1$ & $14(51.8 \%)$ & $19(65.5 \%)$ & 0.30 \\
\hline & $2+3$ & $13(48.1 \%)$ & $10(34.4 \%)$ & 0.31 \\
\hline
\end{tabular}

Abbreviations: $\mathrm{AH}$, alcoholic hepatitis; $\mathrm{ACLF}$, acute-on-chronic liver failure; $\mathrm{CAM}$, complementary and alternative medicine.

patients in the CAM group had cholestasis on liver biopsy ( $n=20 / 27,74.1 \%$ vs. $n=6 / 29,20.7 \% ; p<0.001$ ). Regarding the type of cholestasis, cholangiolar cholestasis was seen only in patients of AH on CAM therapy $(44.4 \%$ vs. $0 \%, p<$ 0.001 ), while hepatocellular and canalicular cholestasis, even though observed among both groups, was significantly higher in $\mathrm{AH}$ patients consuming CAMs (74.1\% vs. $20.7 \% ; p<0.001$ and $40.7 \%$ vs. $15.4 \% ; p=0.003$ respectively). Sinusoidal fibrosis and sinusoidal dilatation were significantly more frequent in patients with $\mathrm{AH}$ on CAM therapy. Liver histopathology of none of the patients revealed classical features of autoimmune hepatitis. Table 3 shows the detailed liver biopsy comparisons between groups, and the pertinent and specific liver histology features associated with AH consuming CAMs patients is shown in Fig. 2.

\section{Patient outcomes}

At the end of 1-, 3- and 6-months follow-up, the proportion of patients surviving in the $\mathrm{AH}$ consuming CAMs group in comparison to the classical AH group were $37.04 \%$ vs. $82.76 \%(p<0.001), 29.63 \%$ vs. $62.1 \%$ and $18.52 \%$ $(p=0.002)$ vs. $51.72 \%(p=0.001)$ respectively. A significantly higher proportion of patients died early on, during the course of $\mathrm{AH}$ when exposed to CAM treatments (Fig. 3). Sepsis was the most common cause of death among both groups (AH consuming CAMs $45.5 \%$ vs. classical AH $64.3 \%$ ) followed by progressive liver failure (Supplementary Table 1).

\section{CAMs and chemical analysis of retrieved drugs}

Only six ( $n=27,22.2 \%)$ patients with suspected AH-related jaundice approached a registered Ayurveda practitioner for treatments, while the majority took treatments from unregistered, unregulated local traditional Ayurvedic healers or underwent self-treatment with herbal medicines. A total of
87 CAMs were consumed by 27 patients, of which identification of at least one component in the CAM was possible only in $40.7 \%$ of patients. Eight patients ingested four CAMs, seventeen ingested three CAMs, and two patients consumed two CAM products each. The mean duration of CAM intake was $10.6 \pm 5.7$ days (min-max, 3-21 days). A detailed list of identifiable CAMs confirmed retrospectively is shown in Supplementary Table 2 . We could retrieve 42 samples of CAM from the patients in retrospect. Complete toxicology analysis of the retrieved CAM products revealed unsettling data regarding quality of manufacturing, adulteration practices and presence of a multitude of liver and other organ toxicity-promoting organic as well as inorganic components. A comprehensive list of these CAMs, along with the complete chemical analysis findings, are shown in Supplementary Table 3. Representational images of some of the retrieved CAMs are shown in Fig. 4. Disclosure of components as well as potentially toxic ingredients were available in less than $40 \%$ of the retrieved samples. For example, the presence of 'excreta of baby elephant' as well as 'semen of the Civet cat' as a CAM constituent was disclosed in a drug ('Dhanwantaram Gulika', see Fig. 4 for more detail). The pertinent findings on chemical analysis and toxicology included adulteration with topical antifungal agents, nonsteroidal anti-inflammatory drugs (like aspirin and diclofenac), alcohols, antimicrobials (such as amoxycillin, lincomycin and salinomycin), chemotherapeutic agents, hazardous industrial solvents, pesticides, herbicides, insecticide components, neuropsychiatric drugs, recreational drug components, anticoagulants, mood enhancers, mutagens, diuretics (spironolactone), sedatives, antidepressants and anticonvulsant drugs, as well as poisonous sesquiterpenes. With regards to heavy metal identification, lead was the most commonly detected (36 samples, $85.7 \%, \max 73.3 \mathrm{mg} / \mathrm{kg}$ ) followed by nickel $(33,78.6 \%$, $\max 73.2 \mathrm{mg} / \mathrm{kg})$, arsenic $(29,69.1 \%$, max $119.4 \mathrm{mg} / \mathrm{kg})$, mercury $(25,59.5 \%, \max 8 \mathrm{mg} / \mathrm{kg})$ and manganese $(20$, 
Philips C.A. et al: CAM use in alcoholic hepatitis and outcomes

Table 2. Patient investigational characteristics between groups

\begin{tabular}{|c|c|c|c|c|c|c|c|}
\hline Group descriptive & Group & $n$ & Mean & Median & SD & SE & $p$ value \\
\hline \multirow[t]{2}{*}{ Age (years) } & $\mathrm{AH}-\mathrm{CAM}$ & 27 & 45.85 & 44.0 & 9.77 & 1.88 & \multirow[t]{2}{*}{0.18} \\
\hline & $\mathrm{AH}$ & 29 & 49.41 & 51.0 & 9.84 & 1.83 & \\
\hline \multirow[t]{2}{*}{ Hemoglobin (g/L) } & $\mathrm{AH}-\mathrm{CAM}$ & 27 & 9.74 & 9.8 & 1.87 & 0.36 & \multirow[t]{2}{*}{0.78} \\
\hline & $\mathrm{AH}$ & 29 & 10.01 & 10.1 & 2.41 & 0.45 & \\
\hline \multirow[t]{2}{*}{ WBC count $\left(\times 1000 / \mathrm{mm}^{3}\right)$} & $\mathrm{AH}-\mathrm{CAM}$ & 27 & 13.21 & 14.7 & 5.18 & 1.00 & \multirow[t]{2}{*}{0.29} \\
\hline & $\mathrm{AH}$ & 29 & 12.63 & 10.9 & 7.68 & 1.43 & \\
\hline \multirow[t]{2}{*}{ Platelet count $\left(\times 10^{9} / \mathrm{L}\right)$} & AH-CAM & 27 & 99.85 & 81.0 & 64.36 & 12.39 & \multirow[t]{2}{*}{0.02} \\
\hline & $\mathrm{AH}$ & 29 & 115.55 & 101.0 & 47.68 & 8.85 & \\
\hline \multirow[t]{2}{*}{ Total bilirubin (mg/dL) } & $\mathrm{AH}-\mathrm{CAM}$ & 27 & 18.80 & 18.6 & 9.73 & 1.87 & \multirow[t]{2}{*}{0.007} \\
\hline & $\mathrm{AH}$ & 29 & 12.61 & 10.2 & 6.77 & 1.26 & \\
\hline \multirow[t]{2}{*}{ AST (IU/L) } & $\mathrm{AH}-\mathrm{CAM}$ & 27 & 129.04 & 120.0 & 87.95 & 16.93 & \multirow[t]{2}{*}{0.44} \\
\hline & $\mathrm{AH}$ & 29 & 143.38 & 92.0 & 119.26 & 22.15 & \\
\hline \multirow[t]{2}{*}{ ALT (IU/L) } & $\mathrm{AH}-\mathrm{CAM}$ & 27 & 63.59 & 46.0 & 46.52 & 8.95 & \multirow[t]{2}{*}{0.84} \\
\hline & $\mathrm{AH}$ & 29 & 81.34 & 48.0 & 93.73 & 17.41 & \\
\hline \multirow[t]{2}{*}{ ALP (IU/L) } & $\mathrm{AH}-\mathrm{CAM}$ & 27 & 146.33 & 142.0 & 58.73 & 11.30 & \multirow[t]{2}{*}{0.90} \\
\hline & $\mathrm{AH}$ & 29 & 169.38 & 134.0 & 106.56 & 19.79 & \\
\hline \multirow[t]{2}{*}{ GGT (IU/L) } & $\mathrm{AH}-\mathrm{CAM}$ & 27 & 222.89 & 184.0 & 156.32 & 30.08 & \multirow[t]{2}{*}{0.18} \\
\hline & $\mathrm{AH}$ & 29 & 168.83 & 141.0 & 116.12 & 21.56 & \\
\hline \multirow[t]{2}{*}{ Serum albumin (mg/dL) } & $\mathrm{AH}-\mathrm{CAM}$ & 27 & 2.67 & 2.8 & 0.41 & 0.08 & \multirow[t]{2}{*}{0.43} \\
\hline & $\mathrm{AH}$ & 29 & 2.84 & 2.7 & 0.55 & 0.10 & \\
\hline \multirow[t]{2}{*}{ INR } & $\mathrm{AH}-\mathrm{CAM}$ & 27 & 2.53 & 2.2 & 0.83 & 0.16 & \multirow[t]{2}{*}{0.71} \\
\hline & $\mathrm{AH}$ & 29 & 2.61 & 2.4 & 0.83 & 0.15 & \\
\hline \multirow[t]{2}{*}{ Sodium (mmol/L) } & $\mathrm{AH}-\mathrm{CAM}$ & 27 & 128.74 & 130.0 & 4.74 & 0.91 & \multirow[t]{2}{*}{0.22} \\
\hline & $\mathrm{AH}$ & 29 & 130.00 & 131.0 & 5.87 & 1.09 & \\
\hline Potassium (mmol/L) & $\mathrm{AH}-\mathrm{CAM}$ & 27 & 4.11 & 4.1 & 0.78 & 0.15 & 0.95 \\
\hline & $\mathrm{AH}$ & 29 & 4.09 & 4.2 & 0.86 & 0.16 & \\
\hline Blood urea $(\mathrm{mg} / \mathrm{dL})$ & $\mathrm{AH}-\mathrm{CAM}$ & 27 & 39.78 & 29.0 & 30.03 & 5.78 & 0.87 \\
\hline & $\mathrm{AH}$ & 29 & 47.62 & 27.0 & 49.38 & 9.17 & \\
\hline Creatinine $(\mathbf{m g} / \mathrm{dL})$ & $\mathrm{AH}-\mathrm{CAM}$ & 27 & 1.31 & 1.0 & 0.71 & 0.14 & 0.93 \\
\hline & $\mathrm{AH}$ & 29 & 1.53 & 1.1 & 1.16 & 0.22 & \\
\hline DF & $\mathrm{AH}-\mathrm{CAM}$ & 27 & 88.74 & 80.8 & 31.14 & 5.99 & 0.01 \\
\hline & $\mathrm{AH}$ & 29 & 68.58 & 61.0 & 30.23 & 5.61 & \\
\hline CTP & $\mathrm{AH}-\mathrm{CAM}$ & 27 & 12.63 & 13.0 & 1.11 & 0.21 & 0.01 \\
\hline & $\mathrm{AH}$ & 29 & 11.62 & 12.0 & 1.54 & 0.29 & \\
\hline MELD sodium & $\mathrm{AH}-\mathrm{CAM}$ & 27 & 31.41 & 30.0 & 4.61 & 0.89 & 0.65 \\
\hline & $\mathrm{AH}$ & 29 & 30.31 & 31.1 & 5.87 & 1.09 & \\
\hline ACLF grade & $\mathrm{AH}-\mathrm{CAM}$ & 27 & 1.44 & 1.0 & 1.25 & 0.24 & 0.08 \\
\hline & $\mathrm{AH}$ & 29 & 0.90 & 0.0 & 1.11 & 0.21 & \\
\hline CLIF C ACLF score & $\mathrm{AH}-\mathrm{CAM}$ & 27 & 60.41 & 58.0 & 15.23 & 2.93 & 0.38 \\
\hline & $\mathrm{AH}$ & 29 & 57.38 & 57.0 & 9.86 & 1.83 & \\
\hline CLIF score & $\mathrm{AH}-\mathrm{CAM}$ & 27 & 11.30 & 11.0 & 2.64 & 0.51 & 0.001 \\
\hline & $\mathrm{AH}$ & 29 & 9.21 & 9.0 & 2.14 & 0.40 & \\
\hline
\end{tabular}

Abbreviations: ACLF, acute-on-chronic liver failure; $\mathrm{AH}$, alcoholic hepatitis; ALP, alkaline phosphatase; ALT, alanine aminotransferase; AST, aspartate aminotransferase; CAM, complementary and alternative medicine; CLIF, chronic liver failure; CTP, Child Turcotte Pugh score; DF, discriminant function; GGT, gamma glutamyl transpeptidase; INR, international normalized ratio; MELD, model for end-stage liver disease score; SD, standard deviation; SE, standard error. 
Philips C.A. et al: CAM use in alcoholic hepatitis and outcomes

Table 3. Liver biopsy characteristics between groups

\begin{tabular}{|c|c|c|c|}
\hline Histology findings & $\mathrm{AH}-\mathrm{CAM}$ group, $n=27$ & Classical AH group, $n=29$ & $p$ value \\
\hline Steatosis & $100 \%$ & $100 \%$ & \\
\hline \multirow[t]{3}{*}{ Grading of steatosis } & Mild $48.1 \%$ & Mild $13.8 \%$ & 0.02 \\
\hline & Moderate $44.4 \%$ & Moderate $65.5 \%$ & \\
\hline & Severe $7.4 \%$ & Severe $20.7 \%$ & \\
\hline \multirow[t]{2}{*}{ Predominant inflammation } & Lymphocyte $63 \%$ & Lymphocytes $10.3 \%$ & $<0.001$ \\
\hline & Neutrophils $37 \%$ & Neutrophils $89.7 \%$ & \\
\hline \multirow[t]{3}{*}{ Predominant site of inflammation } & Lobular 0\% & Lobular $75.9 \%$ & \\
\hline & Portal $77.8 \%$ & Portal $0 \%$ & $<0.001$ \\
\hline & Lobular + portal $22.2 \%$ & Lobular + portal $24.1 \%$ & \\
\hline Ballooning & $100 \%$ & $100 \%$ & \\
\hline Interface hepatitis & $70.4 \%$ & $0 \%$ & $<0.001$ \\
\hline Mallory Denk bodies & $77.8 \%$ & $100 \%$ & 0.007 \\
\hline Neutrophilic satellitosis & $29.6 \%$ & $55.2 \%$ & 0.05 \\
\hline Megamitochondria & $7.4 \%$ & $27.6 \%$ & 0.05 \\
\hline Pericellular fibrosis & $100 \%$ & $100 \%$ & \\
\hline Cirrhosis & $81.5 \%$ & $89.7 \%$ & 0.38 \\
\hline Plasma cells (portal, lobular or interface) & $37 \%$ & $6.9 \%$ & 0.006 \\
\hline $\begin{array}{l}\text { Eosinophilic infiltration (portal, lobular or } \\
\text { interface) }\end{array}$ & $44.4 \%$ & $0 \%$ & $<0.001$ \\
\hline Cholestasis & $74.1 \%$ & $20.7 \%$ & $<0.001$ \\
\hline \multirow[t]{3}{*}{ Type of cholestasis } & Hepatocellular $74.1 \%$ & Hepatocellular $20.7 \%$ & $<0.001$ \\
\hline & Canalicular $40.7 \%$ & Canalicular $6.9 \%$ & 0.003 \\
\hline & Cholangiolar $44.4 \%$ & Cholangiolar $0 \%$ & $<0.001$ \\
\hline Foamy degeneration & $40.7 \%$ & $17.2 \%$ & 0.05 \\
\hline Necrosis (any type) & $70.4 \%$ & $17.2 \%$ & $<0.001$ \\
\hline \multirow[t]{6}{*}{ Patterns of necrosis } & Periportal necrosis $25.9 \%$ & Periportal necrosis $0 \%$ & 0.004 \\
\hline & $\begin{array}{l}\text { Perivenular necrosis } \\
22.2 \%\end{array}$ & $\begin{array}{l}\text { Perivenular necrosis } \\
10.3 \%\end{array}$ & 0.23 \\
\hline & Spotty necrosis $14.8 \%$ & Spotty necrosis $6.9 \%$ & 0.90 \\
\hline & Bridging necrosis $25.9 \%$ & Bridging necrosis $0 \%$ & 0.003 \\
\hline & Confluent necrosis $25.9 \%$ & Confluent necrosis $0 \%$ & 0.004 \\
\hline & $\begin{array}{l}\text { Submassive necrosis } \\
18.5 \%\end{array}$ & Submassive necrosis $0 \%$ & 0.02 \\
\hline Hepatocyte rossetting & $11.1 \%$ & $0 \%$ & 0.07 \\
\hline Sinusoidal dilatation & $33.3 \%$ & $0 \%$ & $<0.001$ \\
\hline Sinusoidal fibrosis & $44.4 \%$ & $7 \%$ & 0.001 \\
\hline
\end{tabular}

Abbreviations: AH, alcoholic hepatitis; CAM, complementary and alternative medicine.

$47.6 \%, \max 824.2 \mathrm{mg} / \mathrm{kg}$ ). The complete quantification levels of heavy metals and the permissible limits of daily oral exposure is shown in Table 4.

\section{Discussion}

In this novel study, we determined the clinical outcomes and liver histopathology of $\mathrm{AH}$ patients undergoing complementary and alternative therapy with Ayurvedic drugs, both proprietary and traditional. Our study brings forth many important aspects in CAM-seeking health behavior and its outcomes among patients with acute liver disease, such as $\mathrm{AH}$. Foremost in this regard is the lack of proper investigational acumen among CAM practitioners to understand and stratify patients with severe $\mathrm{AH}$. Only one-third of the patients approaching a CAM practitioner underwent baseline liver function tests, mostly driven by patient request. This is in agreement with previous publications on CAM that impress on the fact that adequate clinical evaluation, quality of treatment options as well as services provided are in the absence of 

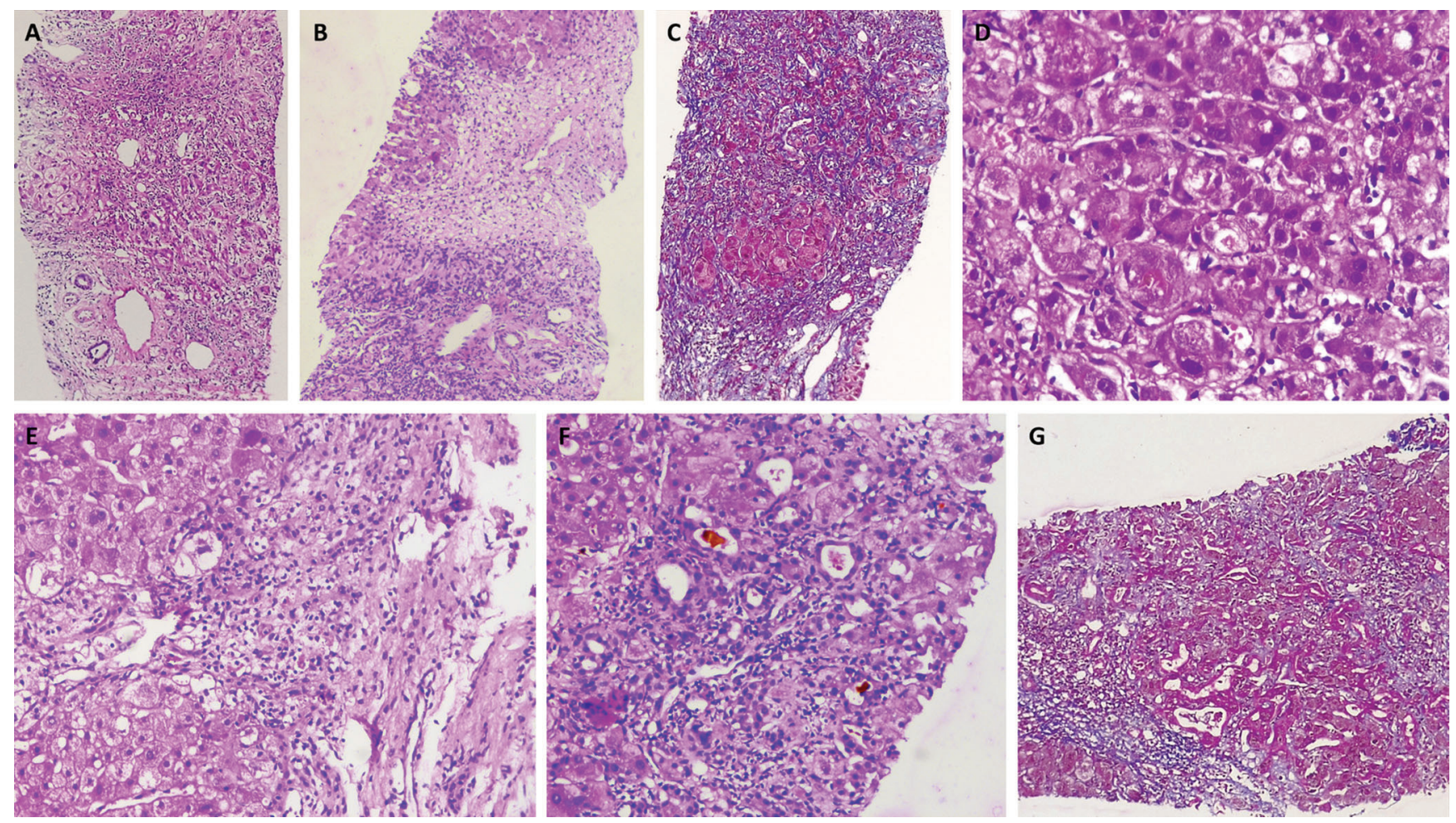

Fig. 2. Liver histopathology features of alcoholic hepatitis patients on Ayurvedic and herbal medications. A. Extensive liver cell necrosis in a patient with severe alcoholic hepatitis associated with ballooned hepatocytes, Mallory-Denk bodies and mixed inflammatory reaction predominated with lymphocytes and eosinophils (hematoxylin and eosin, $\mathrm{x} 40$ ). B. Confluent necrosis in a patient with multiple unknown polyherbal Ayurvedic medications (hematoxylin and eosin, $\mathrm{x} 100$ ). C. Clusters of ballooned hepatocytes surrounded by submassive necrosis and pericellular fibrosis due to consumptions of multiple Ayurvedic products after diagnosis of alcoholic liver disease (Masson-trichrome stain, x100). D. Extensive ballooned hepatocytes with Mallory-Denk bodies, with hepatocellular and cholangiolar cholestasis associated with herbal drug intake (hematoxylin and eosin, x400). E. Mixed inflammatory cells of lymphocytes and eosinophils in the portal areas with surrounding ballooned hepatocytes in a patient with severe alcoholic hepatitis with herbal drug-induced liver injury (hematoxylin and eosin, $\mathrm{x} 400$ ). F. Severe canalicular cholestasis associated with liver cell necrosis and ballooning of hepatocytes seen in a patient consuming Ayurvedic supplements for alcoholic hepatitis (hematoxylin and eosin, x400). G. Extensive bridging necrosis associated with mixed cellular inflammation and pericellular fibrosis in a patient with severe alcoholic liver disease after consuming traditional Ayurvedic medicines (Masson trichrome stain, $x 100)$.
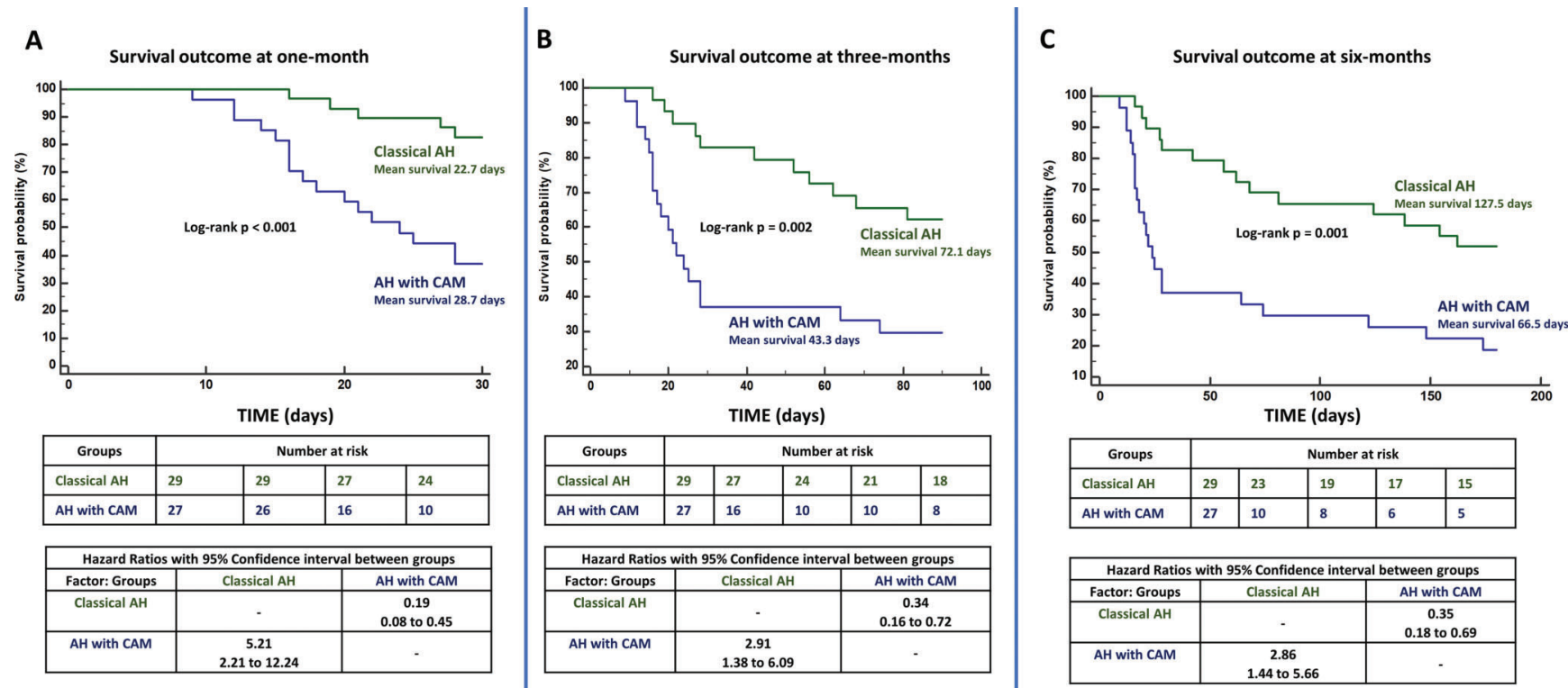

Fig. 3. Kaplan-Meier survival analysis' graphical representation between groups at end of 1-, 3- and 6-months. 

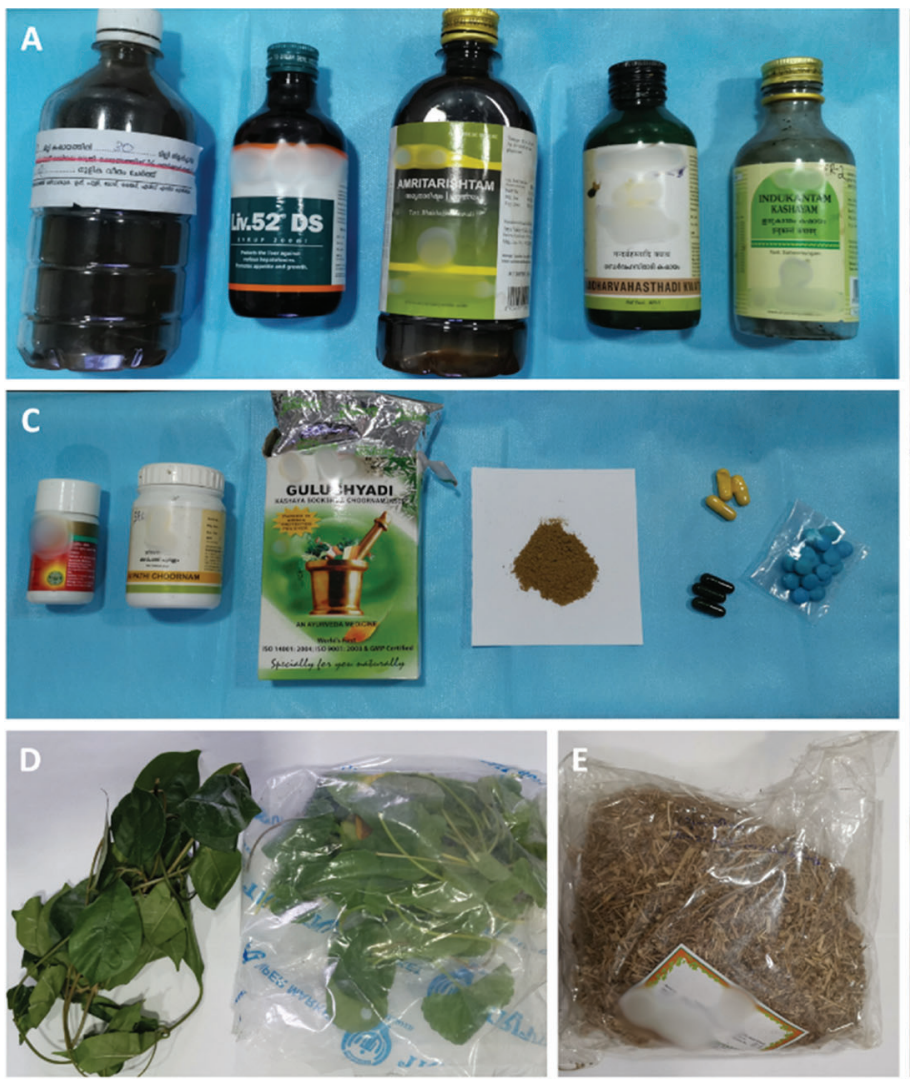
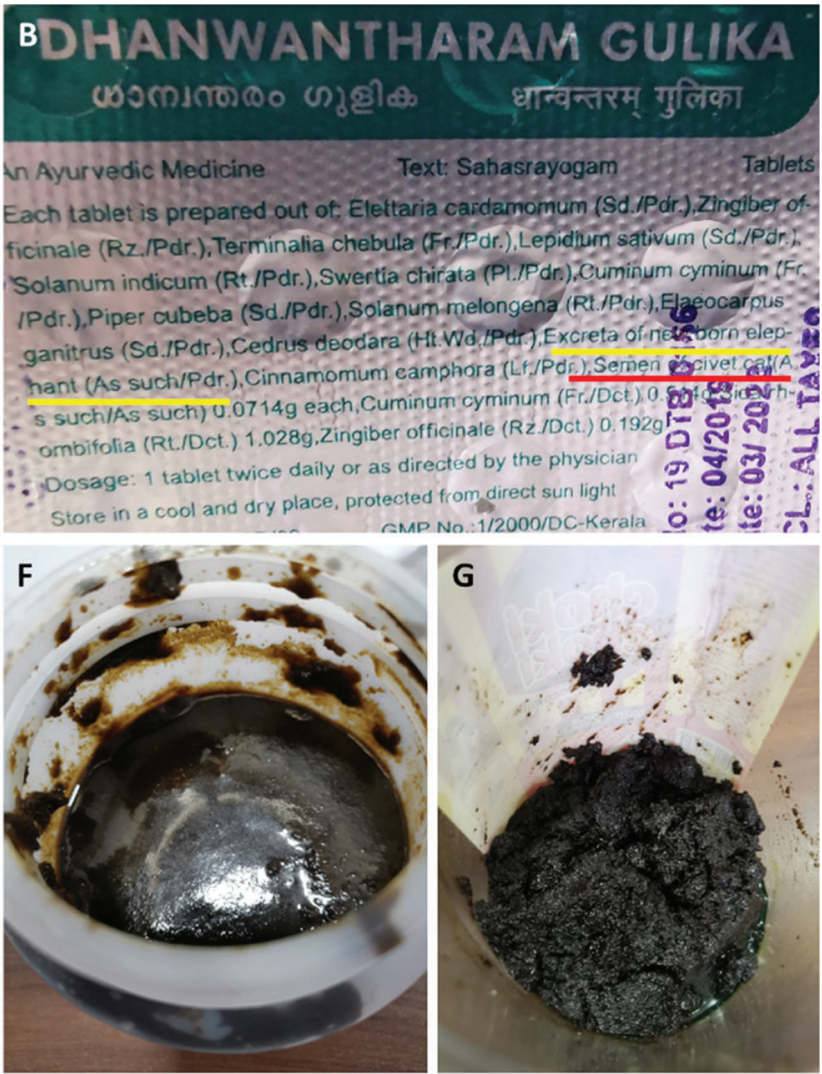

G

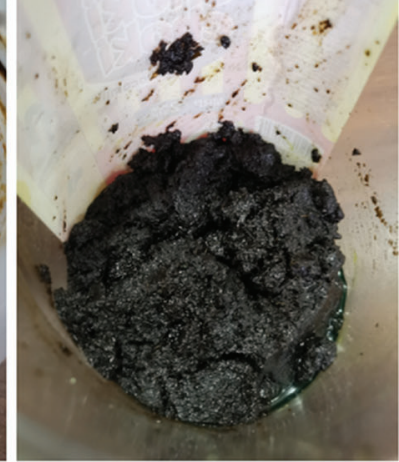

Fig. 4. Example of retrieved Ayurvedic and herbal medicines. A. Traditional Ayurvedic medications prepared and marketed by various pharmaceutical companies, with some lacking proper ingredient labelling, adverse effect notification and maximal dosing for use; labelled ingredients in an Ayurvedic formulation called 'Dhanwantaram Gulika', which was given for nausea, anorexia and overall 'liver health'. B. The components mentioned include fresh excreta of baby elephant (yellow lined) as well as semen of the Civet cat (red lined). C. Some of the formulations came as powders contained in plain papers and unlabeled capsules, tablets and pills. D, E. Freshly plucked (D) and dried herbs (E) were a major part of CAMs utilized by alcoholic hepatitis patients, prescribed by traditional unregistered healers. F, G. Traditional Ayurvedic healer-prepared thick syrups $(F)$ and unlabeled, unknown semi-solid material $(G)$, made out of multiple herbs and powders.

identifiable benefits. ${ }^{23}$ Even though we looked at outcomes only in patients with $\mathrm{AH}$, it was already shown that alcoholic liver disease and alcohol use were among the important factors associated with CAM-seeking behavior among patients with cirrhosis. ${ }^{15}$

In our study, the AH consuming CAMs group of patients had more severe liver disease, higher grades of portal hypertensive complications and poorer clinical outcomes. The survival rates in the short and long term were appalling, due to the fact that liver-related events were higher in the absence of strong recommendations to treatment for severe DILI in an already sick cohort of patients. Several authors have already cautioned against and implored on the sensible use of natural medicine for liver diseases. ${ }^{24}$ The liver disease severity scores and $\mathrm{AH}$ severity were higher among patients in the CAM group. In the current study, we found that several specific findings predominated in $\mathrm{AH}$ patients on CAM therapy. Notable among these was the presence of severe grades of necrosis, interface hepatitis, eosinophilic infiltration, and lesser degrees of steatosis and Mallory-Denk bodies. The presence of necrosis in patients with CAM induced DILI, among both the general population and cirrhosis patients, has been previously documented to promote worse outcomes. ${ }^{5,6}$

To the best of our abilities, we were able to retrieve a good proportion of the CAMs ingested by the patients at the start of their clinical symptoms. On analysis of these agents, we were able to clearly identify a multitude of liver toxic ingredients and undisclosed poisonous substances and multiple adulterants (mostly modern medicine related). Antimicrobials, including topical agents, pain killers, poisonous hazardous chemicals, chemotherapeutic agents, mood enhances, antidepressants, sedatives and heavy metals were found in a large proportion of CAMs analyzed as per state-of-the-art methodology. This finding agrees with previous studies which have showcased toxic levels of heavy metals, mislabeling of herbal products and volatile organic compounds, and heavy metal-related higher death rates among patients on unidentified and complex CAMs. ${ }^{6,9,25,26}$ Our study also confirms the fact that certain well known and currently heavily utilized proprietary Ayurvedic agents (such as Himalaya ${ }^{\circledR}$ Liv.52) is associated with high death rate among patients with advanced liver disease. This particular product has undergone extensive preclinical study, mostly from the Indian subcontinent, from the year 1966 up until 2012, without any quality trials to confirm its true efficacy in human related liver diseases. The only high quality multicenter randomized controlled trial of Liv.52 ${ }^{\circledR}$ for cirrhosis in humans conducted by Fleig et al. ${ }^{27}$ was abruptly stopped in view of higher mortality seen in Child Pugh class $C$ patients, leading to the drug's withdrawal in the United States. 
Table 4. Heavy metal** analysis and quantification in retrieved Ayurvedic samples

\begin{tabular}{lllllll}
\hline Total samples, $n=42$ & Detected, $n(\%)$ & Minimum $^{1} *$ & Maximum $^{2} *$ & Mean $^{3} *$ & Median $^{4} *$ & SD $^{*}$ \\
\hline Aluminum & $7(16.6 \%)$ & 18.560 & 418.400 & 130.380 & 68.850 & 142.2248 \\
Arsenic & $29(69.1 \%)$ & 0.0100 & 119.430 & 13.963 & 0.400 & 33.3589 \\
Gold & $13(30.9 \%)$ & 0.0400 & 1.440 & 0.662 & 0.480 & 0.5816 \\
Mercury & $25(59.5 \%)$ & 0.0100 & 8.010 & 0.673 & 0.190 & 1.5854 \\
Manganese & $20(47.6 \%)$ & 0.640 & 824.170 & 74.031 & 19.720 & 182.0916 \\
Nickel & $33(78.6 \%)$ & 0.200 & 73.290 & 7.461 & 2.150 & 14.2936 \\
Lead & $36(85.7 \%)$ & 0.0800 & 73.370 & 7.129 & 1.465 & 13.7904 \\
Thallium & $18(42.8 \%)$ & 0.0100 & 2.400 & 0.432 & 0.250 \\
\hline
\end{tabular}

*values in $\mathrm{mg} / \mathrm{kg}$.

** the level below which there is low risk for human ill health for arsenic is $0.07 \mathrm{mg} / \mathrm{kg}$; the permissible tolerable weekly intake (PTWI) for mercury is $1.6 \mu \mathrm{g} / \mathrm{kg}$ body weight; PTWI of aluminum is $1 \mathrm{mg} / \mathrm{kg}$ of body weight; tolerable upper limit of manganese is $11 \mathrm{mg}$ per day; tolerable daily intake for nickel is $5 \mu \mathrm{g} / \mathrm{kg}$ body weight; permissible daily oral exposure (PDE) of gold is $134 \mu \mathrm{g} / \mathrm{kg}$; PDE of lead is $5 \mu \mathrm{g}$ per day and of thallium is $8 \mu \mathrm{g}$ per day.

From U. S. Department of Health and Human Services Food and Drug Administration, Center for Drug Evaluation and Research (CDER) and Center for Biologics Evaluation and Research (CBER), Guidance for Industry 2015 update. Retrieved from https://www.fda.gov/regulatory-information/search-fda-guidance-documents/q3d-elementalimpurities on 3/10/2019.

The toxicity of Ayurvedic preparations, even leading to cluster-poisoning, with respect to poor manufacturing practices and unregulated quality checks has been published immensely in literature. ${ }^{28,29}$ Previous studies have also shown that heavy metal contamination and exposure could potentiate a multitude of liver disease, both acute and chronic. ${ }^{30,31}$ Our study is important from two perspectives - one, the patient and family needs to be educated with respect to sensible health-seeking behavior for possible severe liver diseases, so as to reduce morbidity and mortality, and two being the educating and integrating of CAM practitioners to identify patients with potential severe liver disease who require early referrals, so as to initiate proper evidence-based treatment to improve clinical outcomes. Our findings also substantiate the use of liver
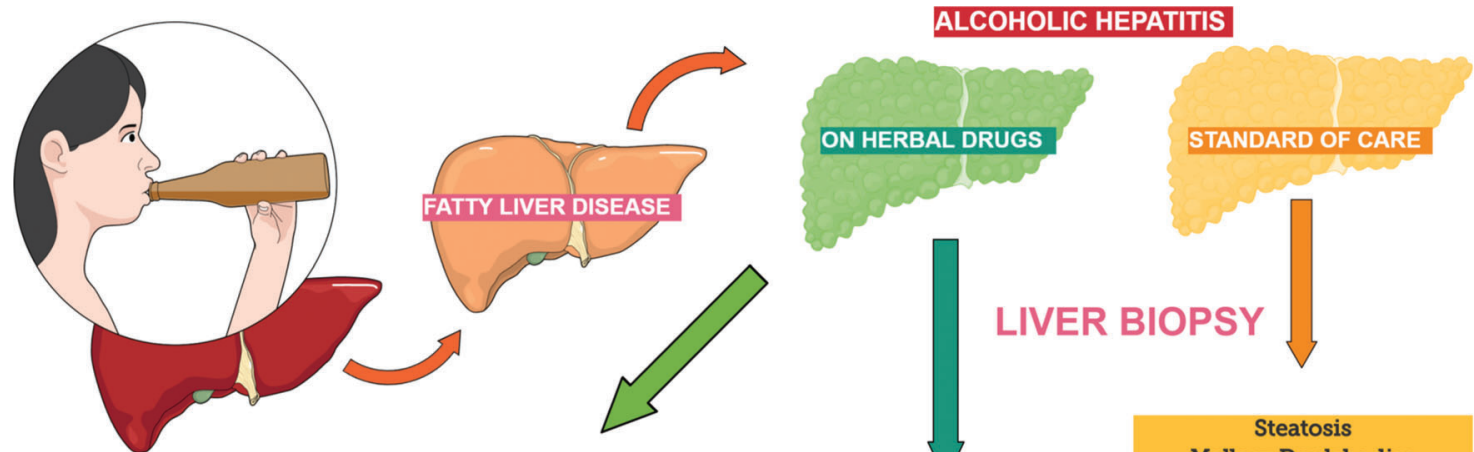

\section{ANALYSIS OF RETRIEVED DRUGS}

a. Unknown, unlabelled, undisclosed component polyherbal formulations most common

b. Traditional healer > registered Ayurveda practitioners

c. Most patients consumed $>3$ different CAMs at a time

d. Lead, Nickel, Arsenic most commonly detected, 1000 to $100,000 x$ more than upper limits of normal

e. Components of approved Ayurveda drugs include excreta of baby elephant and Civet cat semen

\section{ADULTERANTS}

Antibiotics (amoxycillin, lincomycin)

NSAIDS (Diclofenac, aspirin)

Antidepressants (Metapramine)

Anxiolytics, sedatives (Clonazepam, oleamide, adrafinil)

Psychotropic agents, mood-enhancers (ethanol, piracetam,

butanones)

Chemotherapeutic agents (chlorambucil)

Diuretics (spironolactone)

Poisons (Ledol)

Herbicide, insecticide and pesticide components

Fig. 5. Visual abstract summary infographic of the study.

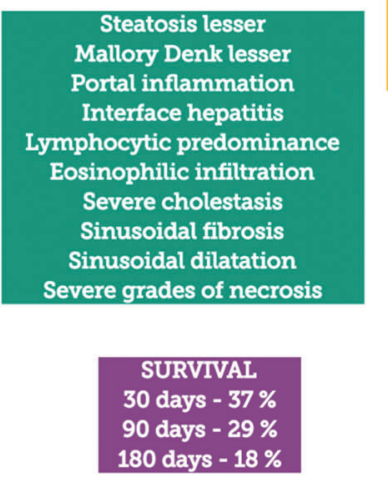

Steatosis
Mallory Denk bodies Neutrophilic satellitosis Lobular inflammation Neutrophilic predominance Perisinusoidal fibrosis

SURVIVAL

30 days $-83 \%$

90 days $-62 \%$

180 days $-52 \%$ 
biopsy in patients with severe AH to identify occult CAM use to tailor specific medical treatments and to define specific patterns of injury associated with high mortality to potentiate early liver transplant referral. Nickel, lead, mercury, arsenic and manganese have been shown to induce acute as well as chronic hepatic injury in animal models and human subjects. The injuries have been demonstrated to range from transaminase elevations to hepatocyte necrosis and in the case of arsenic, occurrence of portal hypertension. ${ }^{32-39}$ Food- and drug-grade substances are recommended to be devoid such contaminants since continued exposure associated with long-term consumption could lead to potential liver injury. The recommended maximal exposures to heavy metals are for environmental soil and water sources and not for food or drug components and must not be referenced synonymously.

Our study has strengths as well as weaknesses. This is the first study to describe and analyze a large group of patients with $\mathrm{AH}$ on CAM treatments from clinical, histopathological and toxicology points of view, underlining important clinical and liver histological aspects that can help differentiate dual insults in $\mathrm{AH}$ patients as well as prognosticate regarding transplant-free survival. All our patients, in both groups, underwent liver biopsy, leaving no room for doubt on the type and patterns of liver injury in this study. We also identified significant adulteration and presence of undisclosed components in a multitude of CAM agents analyzed that calls for proper regulation from the government agencies concerned, in close participation with the industry. Our study limitations are that it was retrospective in nature and from a single center. Even though we systematically compiled and analyzed our patient groups, other rare or atypical causes for liver disease apart from the suspected alcohol and CAM-related DILI could have been overseen. The presence of autoantibodies in patients with CAM use could possibly mean an underlying autoimmune phenomenon related to liver injury or autoimmune hepatitis. However, even in the presence of autoantibodies, the evidence for autoimmune hepatitis was negated in all patients on liver biopsy. The presence of autoantibodies associated with herbal medicines has been previously well described, which agrees with our findings. ${ }^{6,25,40}$ We did not apply the Roussel Uclaf Causality Assessment Method (commonly known as RUCAM) to assess DILI causality, since this tool has not been validated in patients with concurrent acute liver injury. However, our biopsy findings inarguably confirmed a second insult, most probably CAM-related DILI due to the heterogeneity in biopsy findings, that skewed from the expected findings. We did not quantify the organic, inorganic and volatile organic compounds in the samples, due to the high costs associated with such analysis as well as difficulties in procuring standards. However, the presence of some of these compounds has been linked to liver injury the in literature, which agrees with our study findings. ${ }^{6,41}$ Analysis of body fluids for toxins and chemicals were not undertaken in view of differences in time to presentation to the hospital, heterogeneity in duration of consumption, and time to consumption and stopping CAMs in the study population. Even though the analytical lab facility was very close to our hospital premises, volatility of drug components and associated changes on analysis could have occurred. Since most of the patients who consumed CAMs did not undergo liver tests at baseline, the presence of $\mathrm{AH}$ at baseline in these are doubtful and the acute liver injury could have been purely due to the ingested CAMs. However, as per clinical criteria, the most possible diagnosis in these patients, prior to CAM use, could have been AH itself.

Patients with severe $\mathrm{AH}$ and associated CAM intake have severely augmented liver injury leading to higher morbidity and mortality than seen with classical AH patients on conservative and evidence-based management. The presence of adulterants such as antimicrobials, topical agents, poisons as well as chemotherapeutic agents and psychiatry prescription drugs in CAM from the Indian subcontinent is clarified (Infographic Fig. 5). The use of CAMs in patients with acute as well as chronic liver diseases must be regulated, and the general and patient population educated with regards to sensible health-seeking behavior. The need for close monitoring and stringent Good Manufacturing Practices in CAM needs an immense upheaval to prevent adulterant-related organ toxicity. Physicians prescribing CAMs need to be educated, with regards to sensible evaluation, timely referrals and incorporation of evidence-based medicine into practice and taught research methodology for improving identification of beneficial CAMs that may become an important component in the armamentarium of modern medicine.

\section{Conflict of interest}

The authors have no conflict of interests related to this publication.

\section{Author contributions}

Prepared the manuscript, wrote the initial draft, collated data, performed analysis (CAP), revised the manuscript, performed additional analysis (SR), collected data and provided critical review of the manuscript (TG), collected data, performed additional analysis and provided critical revisions (RA), collected data and provided critical manuscript revisions (SK), provided critical revisions to the manuscript (PA). All authors finalized the current version of manuscript for submission.

\section{References}

[1] Im GY. Acute alcoholic hepatitis. Clin Liver Dis 2019;23:81-98. doi: 10. 1016/j.cld.2018.09.005.

[2] Woolbright BL, Jaeschke H. Alcoholic hepatitis: Lost in translation. J Clin Transl Hepatol 2018;6:89-96. doi: 10.14218/JCTH.2017.00054.

[3] Wu T, Morgan TR, Klein AS, Volk ML, Saab S, Sundaram V. Controversies in early liver transplantation for severe alcoholic hepatitis. Ann Hepatol 2018; 17:759-768. doi: 10.5604/01.3001.0012.3134.

[4] Weeks SR, Sun Z, McCaul ME, Zhu H, Anders RA, Philosophe B, et al. Liver transplantation for severe alcoholic hepatitis, updated lessons from the world's largest series. J Am Coll Surg 2018;226:549-557. doi: 10.1016/j. jamcollsurg.2017.12.044

[5] Philips CA, Paramaguru R, Augustine P, Rajesh S, Ahamed R, George T, et al. A single-center experience on outcomes of complementary and alternative medicine use among patients with cirrhosis. Hepatol Commun 2019;3:10011012. doi: 10.1002/hep4.1355.

[6] Philips CA, Paramaguru R, Joy AK, Antony KL, Augustine P. Clinical outcomes, histopathological patterns, and chemical analysis of Ayurveda and herbal medicine associated with severe liver injury-A single-center experience from southern India. Indian J Gastroenterol 2018;37:9-17. doi: 10. 1007/s12664-017-0815-8.

[7] Sharp D, Lorenc A, Morris R, Feder G, Little P, Hollinghurst S, et al. Complementary medicine use, views, and experiences: a national survey in England. BJGP Open 2018;2:bjgpopen18X101614. doi: 10.3399/bjgpopen18X101614.

[8] Fernández A, Simian D, Quera R, Flores L, Ibáñez P, Lubascher J, et al. Complementary and alternative medicine in patients with inflammatory bowel disease: A survey performed in a tertiary center in Chile. Complement Ther Med 2018;40:77-82. doi: 10.1016/j.ctim.2018.07.016.

[9] Navarro V, Avula B, Khan I, Verma M, Seeff L, Serrano J, et al. The contents of herbal and dietary supplements implicated in liver injury in the United States 
are frequently mislabeled. Hepatol Commun 2019;3:792-794. doi: 10. 1002/hep4.1346.

[10] Lin NH, Yang HW, Su YJ, Chang CW. Herb induced liver injury after using herbal medicine: A systemic review and case-control study. Medicine (Baltimore) 2019;98:e14992. doi: 10.1097/MD.0000000000014992.

[11] Bernuau JR, Durand F. Herbal medicines in acute viral hepatitis: a ticket for more trouble. Eur J Gastroenterol Hepatol 2008;20:161-163. doi: 10. 1097/MEG.0b013e3282f2bbf7.

[12] Henson JB, Brown CL, Chow SC, Muir AJ. Complementary and alternative medicine use in United States adults with liver disease. J Clin Gastroenterol 2017;51:564-570. doi: 10.1097/MCG.0000000000000617.

[13] Mullin GE. The use of complementary and alternative medicine for liver disease: part II. Nutr Clin Pract 2013;28:277-279. doi: 10. $1177 / 0884533612475133$

[14] Mullin GE. The use of complementary and alternative medicine for liver disease: part I. Nutr Clin Pract 2013;28:138-139. doi: 10.1177/0884533612471766.

[15] Ferrucci LM, Bell BP, Dhotre KB, Manos MM, Terrault NA, Zaman A, et al. Complementary and alternative medicine use in chronic liver disease patients. J Clin Gastroenterol 2010;44:e40-e45. doi: 10.1097/MCG. 0b013e3181b766ed.

[16] Batey RG, Salmond SJ, Bensoussan A. Complementary and alternative medicine in the treatment of chronic liver disease. Curr Gastroenterol Rep 2005; 7:63-70. doi: 10.1007/s11894-005-0068-z.

[17] Singal AK, Louvet A, Shah VH, Kamath PS. Grand rounds: Alcoholic hepatitis. J Hepatol 2018;69:534-543. doi: 10.1016/j.jhep.2018.05.001.

[18] Song NE, Lee JY, Mansur AR, Jang HW, Lim MC, Lee Y, et al. Determination of 60 pesticides in hen eggs using the QuEChERS procedure followed by LCMS/MS and GC-MS/MS. Food Chem 2019;298:125050. doi: 10.1016/j.foodchem.2019.125050.

[19] Mazumder S, Ahamed RA, McGahee E, Wang L, Seyler TH. A new automated method for the analysis of aromatic amines in human urine by GC-MS/MS. J Anal Toxicol 2019;43:25-35. doi: 10.1093/jat/bky045.

[20] Chang QY, Pang GF, Fan CL, Chen H, Yang F, Li J, et al. High-throughput analytical techniques for the determination of the residues of 653 multiclass pesticides and chemical pollutants in tea, Part VII: A GC-MS, GC-MS/MS, and LC-MS/MS study of the degradation profiles of pesticide residues in green tea. J AOAC Int 2016;99:1619-1627. doi: 10.5740/jaoacint.16-0158.

[21] Bernardi G, Kemmerich M, Ribeiro LC, Adaime MB, Zanella R, Prestes OD. An effective method for pesticide residues determination in tobacco by GCMS/MS and UHPLC-MS/MS employing acetonitrile extraction with lowtemperature precipitation and d-SPE clean-up. Talanta 2016;161:40-47. doi: 10.1016/j.talanta.2016.08.015.

[22] Chen X, Li Y, Chang QY, Hu XY, Pang GF, Fan CL. High-throughput analytical techniques for determination of residues of 653 multiclass pesticides and chemical pollutants in tea-Part V: A comparative study of the influence of tea hydration on the efficiency of pesticide multiresidue determination using three sample preparation methods and GC/MS/MS. J AOAC Int 2015;98: 149-159. doi: 10.5740/jaoacint.13-279.

[23] Bloom BS, Retbi A, Dahan S, Jonsson E. Evaluation of randomized controlled trials on complementary and alternative medicine. Int J Technol Assess Health Care 2000;16:13-21. doi: 10.1017/s0266462300016123.

[24] Xiong F, Guan YS. Cautiously using natural medicine to treat liver problems. World J Gastroenterol 2017;23:3388-3395. doi: 10.3748/wjg.v23.i19. 3388.
[25] Devarbhavi H. Ayurvedic and herbal medicine-induced liver injury: It is time to wake up and take notice. Indian J Gastroenterol 2018;37:5-7. doi: 10. 1007/s12664-018-0820-6.

[26] Stolz A, Navarro V, Hayashi PH, Fontana RJ, Barnhart HX, Gu J, et al. Severe and protracted cholestasis in 44 young men taking bodybuilding supplements: assessment of genetic, clinical and chemical risk factors. Aliment Pharmacol Ther 2019;49:1195-1204. doi: 10.1111/apt.15211.

[27] Schuppan D, Jia JD, Brinkhaus B, Hahn EG. Herbal products for liver diseases: a therapeutic challenge for the new millennium. Hepatology 1999 30:1099-1104. doi: 10.1002/hep.510300437.

[28] Manohar PR. Toxicity of Ayurveda medicines and safety concerns: The need to revive the branch of toxicology in Ayurveda. Anc Sci Life 2014;34:1-2. doi: 10.4103/0257-7941.150761.

[29] Mikulski MA, Wichman MD, Simmons DL, Pham AN, Clottey V, Fuortes LJ. Toxic metals in ayurvedic preparations from a public health lead poisoning cluster investigation. Int J Occup Environ Health 2017;23:187-192. doi: 10. 1080/10773525.2018.1447880.

[30] Jan AT, Azam M, Siddiqui K, Ali A, Choi I, Haq QM. Heavy metals and human health: Mechanistic insight into toxicity and counter defense system of antioxidants. Int J Mol Sci 2015;16:29592-29630. doi: 10.3390/ijms161226183.

[31] Jaishankar M, Tseten T, Anbalagan N, Mathew BB, Beeregowda KN. Toxicity, mechanism and health effects of some heavy metals. Interdiscip Toxicol 2014;7:60-72. doi: 10.2478/intox-2014-0009.

[32] Kim J], Kim YS, Kumar V. Heavy metal toxicity: An update of chelating therapeutic strategies. J Trace Elem Med Biol 2019;54:226-231. doi: 10.1016/j. jtemb.2019.05.003.

[33] Fiati Kenston SS, Su H, Li Z, Kong L, Wang $Y$, Song $X$, et al. The systemic toxicity of heavy metal mixtures in rats. Toxicol Res (Camb) 2018;7:396407. doi: $10.1039 / \mathrm{c} 7 \mathrm{tx} 00260 \mathrm{~b}$.

[34] Lin X, Gu Y, Zhou Q, Mao G, Zou B, Zhao J. Combined toxicity of heavy metal mixtures in liver cells. J Appl Toxicol 2016;36:1163-1172. doi: 10.1002/jat. 3283.

[35] Tchounwou PB, Yedjou CG, Patlolla AK, Sutton DJ. Heavy metal toxicity and the environment. Exp Suppl 2012;101:133-164. doi: 10.1007/978-3-76438340-4 6 .

[36] Zeinali T, Salmani F, Naseri K. Dietary intake of cadmium, chromium, copper, nickel, and lead through the consumption of meat, liver, and kidney and assessment of human health risk in Birjand, Southeast of Iran. Biol Trace Elem Res 2019;191:338-347. doi: 10.1007/s12011-019-1637-6.

[37] Yu S, Liu F, Wang C, Zhang J, Zhu A, Zou L, et al. Role of oxidative stress in liver toxicity induced by nickel oxide nanoparticles in rats. Mol Med Rep 2018;17:3133-3139. doi: 10.3892/mmr.2017.8226.

[38] Adjroud O. The toxic effects of nickel chloride on liver, erythropoiesis, and development in Wistar albino preimplanted rats can be reversed with selenium pretreatment. Environ Toxicol 2013;28:290-298. doi: 10.1002/tox. 20719.

[39] Huang P, Chen C, Wang H, Li G, Jing H, Han Y, et al. Manganese effects in the liver following subacute or subchronic manganese chloride exposure in rats. Ecotoxicol Environ Saf 2011;74:615-622. doi: 10.1016/j.ecoenv.2010.08.011.

[40] Sebode M, Schulz L, Lohse AW. "Autoimmune(-like)" drug and herb induced liver injury: New insights into molecular pathogenesis. Int J Mol Sci 2017;18: 1954. doi: 10.3390/ijms18091954.

[41] Lang AL, Beier JI. Interaction of volatile organic compounds and underlying liver disease: a new paradigm for risk. Biol Chem 2018;399:1237-1248. doi: 10.1515/hsz-2017-0324. 